\title{
Radiation Oncology Fellowship: a Value-Based Assessment Among Graduates of a Mature Program
}

\author{
Emma Ito ${ }^{1}$ Fabio Y. Moraes ${ }^{2} \cdot{\text { Matthew } \text { Ramotar }^{1} \cdot \text { Isis Lunsky }^{1} \cdot \text { Hany Soliman }}^{3,4} \cdot$ Charles N. Catton $^{1,3} \cdot$ \\ Zahra Kassam $^{3,5} \cdot$ Gerard Morton $^{3,4} \cdot$ Sarah Tosoni $^{1}$ • Mary Gospodarowicz ${ }^{1,3} \cdot$ Rebecca K.S. Wong ${ }^{1,3} \cdot$ Fei-Fei Liu $^{1,3}$. \\ Peter W. M. Chung ${ }^{1,3}$
}

Published online: 18 July 2020

(C) The Author(s) 2020

\begin{abstract}
The University of Toronto - Department of Radiation Oncology (UTDRO) has had a well-established Fellowship Program for over 20 years. An assessment of its graduates was conducted to evaluate training experience and perceived impact on professional development. Graduates of the UTDRO Fellowship Program between 1991 and 2015 were the focus of our review. Current employment status was collected using online tools. A study-specific web-based questionnaire was distributed to $263 / 293$ graduates for whom active e-mails were identified; questions focused on training experience, and impact on career progression and academic productivity. As a surrogate measure for the impact of UTDRO Fellowship training, a comparison of current employment and scholarly activities of individuals who obtained their Fellow of the Royal College of Physicians of Canada (FRCPC) designation in Radiation Oncology between 2000 and 2012, with $(n=57)$ or without ( $n=230)$ UTDRO Fellowship training, was conducted. Almost all UTDRO Fellowship graduates were employed as staff radiation oncologists (291/293), and most of those employed were associated with additional academic (130/293), research (53/293), or leadership (68/293) appointments. Thirty-eight percent $(101 / 263)$ of alumni responded to the online survey. The top two reasons for completing the Fellowship were to gain specific clinical expertise and exposure to research opportunities. Respondents were very satisfied with their training experience, and the vast majority (99\%) would recommend the program to others. Most (96\%) felt that completing the Fellowship was beneficial to their career development. University of Toronto, Department of Radiation Oncology Fellowship alumni were more likely to hold university, research, and leadership appointments, and author significantly more publications than those with FRCPC designation without fellowship training from UTDRO. The UTDRO Fellowship Program has been successful since its inception, with the majority of graduates reporting positive training experiences, benefits to scholarly output, and professional development for their post-fellowship careers. Key features that would optimize the fellowship experience and its long-term impact on trainees were also identified.
\end{abstract}

Keywords Radiation Oncology $\cdot$ Fellowship $\cdot$ Medical education

Electronic supplementary material The online version of this article (https://doi.org/10.1007/s13187-020-01767-5) contains supplementary material, which is available to authorized users.

Peter W. M. Chung

Peter.Chung@rmp.uhn.ca

1 Radiation Medicine Program, Princess Margaret Cancer Centre, University Health Network, 610 University Avenue, Toronto M5G 2M9, Canada

2 Department of Oncology, Queen's University, Kingston, Ontario, Canada
3 Department of Radiation Oncology, University of Toronto, Toronto, Ontario, Canada

4 Department of Radiation Oncology, Odette Cancer Centre, Sunnybrook Health Sciences Centre, Toronto, Ontario, Canada

5 Stronach Regional Cancer Centre, Newmarket, Ontario, Canada 


\section{Introduction}

Cancer incidence rates are increasing worldwide, with more than $50 \%$ of all cancer patients requiring radiation therapy [1]. As such, radiation oncology (RO) continues to be a growing specialty. In recent years, a steady increase in the number of programs offering $\mathrm{RO}$ fellowship training and the number of clinical RO fellows has been observed [2,3]. Several studies have reported that an increasing proportion of RO residents are extending their training by pursuing post-residency fellowships to enhance clinical and research competencies, as well as to increase their competitiveness in the challenging job market and academic environment [2, 4-6]. RO fellowships, typically spanning 1 to 2 years, offer opportunities to gain subspecialty expertise and skills in specialized technologies and techniques (e.g., brachytherapy, stereotactic radiation therapy, image guided techniques, proton therapy); pursue research projects with potential for high impact academic publication; and network and build collaborations.

The Radiation Oncology Fellowship Program at the University of Toronto - Department of Radiation Oncology is one of the largest of its kind in the world (https://www. radonc.utoronto.ca). Formally established as an independent department in 1991, the Fellowship Program is open to those who have recently completed specialty training in Radiation Oncology in their home country. The program annually attracts a large number of high caliber candidates from across the world, including Asia-Pacific countries, Europe, Africa, and the Americas. Successful candidates are selected through a competitive process with approximately twice the number of applicants versus fellows accepted. Fellows enroll in Clinical Research Fellowships (approximately 1-2 years) at either the Princess Margaret Cancer Centre (University Health Network) or Odette Cancer Centre (Sunnybrook Health Sciences Centre) , both offering rich on-site clinical and research training experiences. As a university-based program for certified specialists that is not accredited by the Royal College of Physicians and Surgeons of Canada (Royal College), a structured programlevel assessment of student learning and training experience has not been conducted to date.

This study represents the first effort to formally evaluate the impact of post-residency fellowship training on the careers of its graduates at a single institution. Our objectives were to (1) describe the characteristics of learners who enrolled in the UTDRO Fellowship Program; (2) examine the trends in current employment status and academic productivity of those completing the UTDRO Fellowship, (3) explore the potential impact on academic productivity by evaluating similar metrics in a non-UTDRO trained cohort, and (4) to explore the strengths and weaknesses of our program as recalled by learners through a study-specific survey. We hypothesized that completion of post-residency fellowship training has a positive impact on graduates' academic output and overall career trajectory. Our findings may help to establish a framework for evaluating the effectiveness of fellowship programs, and to identify key features that would optimize the fellowship experience and its long-term impact on trainees.

\section{Methods and Materials}

Three methods were employed to address our study objectives (Appendix I). First, a retrospective analysis of employment and scholarly activities of individuals who enrolled in the UTDRO Fellowship Program since its formal inception was conducted. Second, a study-specific survey to capture graduates' perceptions of their fellowship experiences and impact on career trajectory was sent to alumni. Third, a comparator cohort was identified to further characterize the potential effect of UTDRO Fellowship training on employment and academic productivity post-residency.

A waiver of consent was granted for this study by the Research Ethics Board at the University Health Network through an expedited review procedure.

\section{Study Population}

\section{Retrospective Cohort}

Graduates of the UTDRO Fellowship Program with an enrollment start date between 1991 and 2015 were identified $(n=$ 293) from departmental records and the Postgraduate Web Evaluation and Registration system hosted by the Faculty of Medicine at the University of Toronto.

\section{Survey Cohort}

University of Toronto, Department of Radiation Oncology Fellowship alumni for whom active e-mails were available $(n=263)$ were sent the UTDRO Fellowship Experience Survey as part of a comprehensive approach for quality improvement and impact assessment.

\section{Comparator Cohort}

Since UTDRO graduates were predominantly from Canada, Australia and the UK, we attempted to identify non-UTDRO trained peers with recognized RO specialty training/ certification within these countries. Our search was limited to RO specialists within Canada, as we were only able to access the public directory of the Royal College of Physicians and Surgeons of Canada.

To characterize the employment and scholarly activities of a contemporary cohort of Canadian RO specialists (minimum of 5 years post-residency), individuals who obtained their Fellow of the Royal College of Physicians of Canada 
(FRCPC) in Radiation Oncology between the years of 2000 and $2012(n=287)$ were identified. Specialty recipients were further divided into two subgroups: UTDRO Fellowship alumni $(n=57)$ and others $(n=230)$.

\section{Data Collection}

\section{Employment Status and Academic Productivity}

An extensive online search of the World Wide Web (Internet) was conducted from May to June 2018 to identify the current country of employment and position(s), as well as academic output and professional (radiation oncology-specific) leadership appointments attained by individuals within the retrospective and comparator cohorts. Multiple online databases were utilized (described in Appendix II) to determine the total number of peer-reviewed articles published by individuals since receiving their FRCPC designation, as well as the number of clinical trials in which individuals were involved as principal investigator or co-investigator.

\section{UTDRO Fellowship Experience Survey}

A 51-question web-based Google Form survey comprised of multiple choice and open-ended questions was sent electronically to the survey cohort. The questionnaire was divided into three sections: (i) the UTDRO Fellowship experience, (ii) career after the UTDRO Fellowship, and (iii) an evaluation of the Fellowship Program. The survey, which required approximately $15 \mathrm{~min}$ to complete, contained questions focused on the individual's experience of the program, how it influenced their career progression and academic productivity post-fellowship, as well as suggestions for programmatic improvement. Individuals were sent a secure explanatory e-mail describing the objective of the project, voluntary nature of participation, and anonymity of the data collection process, as well as a link to access the online survey. The survey was available for completion over a 14-week period (SeptemberDecember 2017), over which time six e-mail reminders were sent to non-responders. Anonymized, aggregate responses from completed surveys were compiled in an Excel database.

\section{Qualitative Analysis}

Thematic analysis $[7,8]$ was conducted on all open-ended survey responses using an inductive approach to identify common shared responses across participants. Responses were grouped based on similar features and classified into common themes which were then ranked from most-to-least mentioned. To ensure inter-rater reliability, two members of the research team conducted analyses independently, with regular meetings to confirm consensus.

\section{Statistical Analysis}

Descriptive statistics were used to summarize the quantitative data and describe survey responses. A $p$ value of $\leq 0.05$ (Mann-Whitney $U$ test) was utilized as the threshold for statistical significance.

\section{Results}

\section{Demographics of UTDRO Fellows}

Between the years of 1991 and 2015, 293 individuals were enrolled in the UTDRO Fellowship Program (Table 1). The median number of fellows accepted annually into the program was 11 (range 1-25). Countries of citizenship were documented for 290 individuals (Appendix III). The majority of fellows were from Canada (29\%), followed by Australia (18\%) or the UK (16\%). Approximately 4\% of fellows were from lowermiddle-income countries (LMICs), including Ghana $(0.3 \%)$ and India (4\%).

Since fellowship completion, most alumni were working in Canada (34\%), Australia (19\%), or the UK (15\%). Almost all alumni were employed as staff radiation oncologists (99\%), and held university faculty appointments $(44 \%)$, research positions (18\%), and/or additional leadership roles (23\%) in clinical, research, or educational programs, as well as regional, national, or international committees and organizations.

\section{Demographics of Survey Respondents}

The UTDRO Fellowship Experience Survey was completed by $38 \%(101 / 263)$ of the survey cohort. Survey respondents (Table 2) were generally more recent alumni compared with the retrospective cohort (Table 1), but had similar distributions in terms of current country of employment and proportion of those hired as staff oncologists. The majority were graduates of Canadian (22\%), UK (22\%), or Australian (14\%) medical schools. Eighty-nine percent of respondents began their fellowship in 2001 or later, with median fellowship duration being 12 months (range 5-64); the majority (52\%) completed their studies between 10 and 14 months. The minimum length of training for fellows was 6 months as defined by the university's Postgraduate Medical Education Office, although the majority of fellows were enrolled in a 12-month program. Occasionally, fellows departed early due to receiving offers for full-time employment prior to the projected end-date of their fellowship. Even so, these fellows were present long enough to achieve their intended goals, and thus were classified as graduates. Most respondents (57\%) were between 30 and 34 years old at the start of their fellowship, and majority had relocated with their family (60\%). Eighty-five percent of respondents elected to enroll in the 1-year Fellowship 
Table 1 Demographics of UTDRO Fellows (1991-2015)

\begin{tabular}{|c|c|c|c|}
\hline & & No. & Percent \\
\hline \multirow[t]{5}{*}{ Year Fellowship started $(n=293)$} & 1991-1995 & 16 & $(5)$ \\
\hline & 1996-2000 & 29 & $(10)$ \\
\hline & $2001-2005$ & 57 & $(20)$ \\
\hline & 2006-2010 & 95 & $(32)$ \\
\hline & 2011-2015 & 96 & (33) \\
\hline \multirow[t]{2}{*}{ Gender $(n=293)$} & Female & 132 & $(45)$ \\
\hline & Male & 161 & $(55)$ \\
\hline \multirow[t]{7}{*}{ Country of citizenship $(n=290)$} & Australia & 53 & (18) \\
\hline & Canada & 83 & (29) \\
\hline & India & 12 & (4) \\
\hline & Ireland & 20 & (7) \\
\hline & New Zealand & 10 & (3) \\
\hline & UK & 46 & (16) \\
\hline & Other & 66 & (23) \\
\hline \multirow[t]{7}{*}{ Country of employment $(n=293)$} & Australia & 56 & (19) \\
\hline & Canada & 100 & (34) \\
\hline & Ireland & 12 & (4) \\
\hline & New Zealand & 11 & (4) \\
\hline & UK & 43 & $(15)$ \\
\hline & USA & 12 & (4) \\
\hline & Other & 59 & $(20)$ \\
\hline \multirow[t]{5}{*}{ Appointment $(n=293)$} & Leadership & 68 & (23) \\
\hline & Research & 53 & (18) \\
\hline & Staff oncologist & 291 & (99) \\
\hline & University faculty & 130 & (44) \\
\hline & $\begin{array}{l}\text { Other (e.g., trainee, non-practicing hospital administra- } \\
\text { tor) }\end{array}$ & 2 & (1) \\
\hline
\end{tabular}

Program and $89 \%$ completed their fellowship at the Princess Margaret Cancer Centre.

\section{Fellowship Objectives and Scholarly Output of Survey Respondents}

The top objectives (Table 7), in order of importance, for pursuing a fellowship at UTDRO were to (1) gain specific clinical expertise, (2) gain exposure to research opportunities with potential to publish, (3) obtain another perspective of radiation oncology in a large academic department, (4) network and build collaborations with world-class academics, and (5) become more competitive in the job market. Almost all (99\%) of the respondents believed that the UTDRO Fellowship had mostly or completely fulfilled these objectives (Table 3). Thematic analyses revealed that the top reasons the fellowship program fulfilled the alum's objectives were (1) clinical experience, (2) research opportunities, (3) networking, (4) mentorship, and (5) that it led to employment (Table 7).
Academic productivity during the fellowship was measured based on manuscript and abstract authorship. Fellows authored a median of 2 peer-reviewed manuscripts and 3 abstracts as first or co-author during their time in the program. A small group of individuals had obtained a Master's (10\%) or Doctoral (4\%) degree during the program. Interestingly, 73\% of respondents felt that their productivity could have been improved during the fellowship. Top factors limiting productivity (Table 7), in order of importance, included insufficient protected research time, limited collaborative opportunities with other fellows, mentorship/supervision, as well as challenges with research (e.g., lack of expertise and resources), and family/personal issues.

\section{Current Clinical and Scholarly Activities of Survey Respondents}

A high percentage of respondents $(68 \%)$ considered practicing in Canada after their fellowship; however, only $31 \%$ of alumni found employment in Canada immediately after graduating 
Table 2 Demographics of survey respondents $(n=101)$

No. Percent

Country of medical school training (top 5)

$\begin{array}{lrl}\text { Canada } & 22 & (22) \\ \text { UK } & 22 & (22) \\ \text { Australia } & 14 & (14) \\ \text { India } & 6 & (6) \\ \text { New Zealand } & 6 & (6) \\ \text { Other } & 31 & (30) \\ \text { Country of radiation oncology training (top 5) } & & \\ \text { Canada } & 29 & (28) \\ \text { UK } & 22 & (22) \\ \text { Australia } & 18 & (18) \\ \text { Chile } & 5 & (5) \\ \text { Switzerland } & 5 & (5) \\ \text { Other } & 22 & (22) \\ \text { Year of Fellowship start } & & \\ \text { 1991-1995 } & 2 & (2) \\ \text { 1996-2000 } & 9 & (9) \\ \text { 2001-2005 } & 22 & (22) \\ \text { 2006-2010 } & 26 & (26) \\ \text { 2011-2015 } & 42 & (41)\end{array}$

Fellowship duration (months)

5-9

$5 \quad(5)$

$10-14$

$15-19$

20-24

$25-29$

$\geq 30$

Age at start of Fellowship

$$
\text { 25-29 years old }
$$

12 (12)

30-34 years old

35-39 years old

$>40$ years old

Relocated with family

$\begin{array}{lll}\text { Yes } & 61 \quad(60)\end{array}$

No

Fellowship location

Odette Cancer Centre $\quad 11 \quad$ (11)

Princess Margaret Cancer Centre $\quad 90 \quad$ (89)

Fellowship type

1-Year clinical fellowship (80\% clinical) $31 \quad$ (31)

1 -Year clinical research fellowship (50\% clinical and $55 \quad$ (54) $50 \%$ research)

2-Year research fellowship (80\% research)

$15 \quad(15)$

Number of survey respondents per question: 101

(Table 4). A small proportion of graduates (17\%) enrolled in another fellowship or training program.

At the time of analysis, all respondents held staff positions in the field of radiation oncology and had been employed in a
Table 3 Fellowship objectives and academic output

\begin{tabular}{|c|c|c|}
\hline & No. & Percent \\
\hline \multicolumn{3}{|c|}{ Additional degrees obtained during Fellowship } \\
\hline Master's Degree & 10 & $(10)$ \\
\hline $\mathrm{PhD}$ & 4 & (4) \\
\hline None & 87 & $(86)$ \\
\hline \multicolumn{3}{|c|}{$\begin{array}{l}\text { Number of peer-reviewed manuscripts resulting from Fellowship (first } \\
\text { author or co-author) }\end{array}$} \\
\hline 0 & 13 & (13) \\
\hline $1-3$ & 54 & $(53)$ \\
\hline $4-6$ & 19 & $(19)$ \\
\hline $7-9$ & 5 & $(5)$ \\
\hline$\geq 10$ & 10 & $(10)$ \\
\hline \multicolumn{3}{|c|}{ Number of abstracts resulting from Fellowship (first author or co-author } \\
\hline 0 & 8 & $(8)$ \\
\hline $1-3$ & 54 & $(53)$ \\
\hline $4-6$ & 19 & (19) \\
\hline $7-9$ & 7 & (7) \\
\hline$\geq 10$ & 13 & (13) \\
\hline \multicolumn{3}{|c|}{ Productivity during Fellowship could have been better } \\
\hline Yes & 41 & $(40)$ \\
\hline Maybe & 33 & (33) \\
\hline No & 27 & $(27)$ \\
\hline \multicolumn{3}{|l|}{ Fellowship fulfilled objectives } \\
\hline Yes & 83 & $(82)$ \\
\hline Mostly & 17 & $(17)$ \\
\hline No & 1 & (1) \\
\hline
\end{tabular}

Number of survey respondents per question: 101

median of 1 department (range 1-4) as staff radiation oncologists since completing the fellowship. Most are currently employed in Canada (30\%), UK (19\%), or Australia (16\%). The majority practiced at university-affiliated institutions $(72 \%)$ in combined academic and clinical roles (55\%); the top three occupations reported were consultant (33\%), assistant professor (22\%), and associate professor (19\%). Respondents typically spent as a median: 60\% (range 0$100 \%$ ) of their time on direct patient care, $10 \%$ (range 0 $70 \%$ ) on research, $10 \%$ (range $0-70 \%$ ) on administration, $10 \%$ on teaching/education (range $0-50 \%$ ), and $0 \%$ (range $0-80 \%)$ on other duties. A large proportion $(61 \%)$ had held management/administrative leadership positions since completing the fellowship.

Most respondents (39\%) had authored 1-5 peer-reviewed publications since graduating, while $26 \%$ had published more than 15 papers. Approximately half (47\%) had ongoing clinical or research collaborations originating from the fellowship; among which, approximately $70 \%$ (33/47) were with UTDRO faculty. 
Table 4 Clinical and scholarly activities after Fellowship

No. Percent

Considered staying in Canada after Fellowship

Yes $\quad 69 \quad(68)$

No 32

Country of employment immediately post-Fellowship (top 5) Canada $31 \quad$ (31)

UK $20 \quad$ (20)

Australia $16 \quad 16$

Switzerland $\quad 6 \quad$ (6)

Chile $\quad 5 \quad(5)$

Other $23 \quad$ (22)

Enrolled in another fellowship or training program after UTDRO Fellowship Yes $\quad 17 \quad(17)$

No $\quad 84 \quad$ (83)

Obtained additional qualifications since completing Fellowship

MBA 2

MSc 99

$\mathrm{PhD} \quad 9 \quad$ (9)

None $\quad 81 \quad(80)$

Number of departments employed as staff oncologist after Fellowship

$1 \quad 70 \quad$ (69)

228

$3 \quad 2 \quad(2)$

$4 \quad 1 \quad$ (1)

Country of current employment (top 5)

Canada $\quad 30 \quad 30)$

UK 19

Australia $16 \quad 16$

Switzerland $\quad 6 \quad$ (6)

USA $\quad 5 \quad$ (5)

Other 25

Type of current practice
Community

$\begin{array}{lrl}\text { Community } & 5 & (5) \\ \text { Mixed } & 18 & (18)\end{array}$

Private 5

University affiliated 73

$\begin{array}{lll}\text { Type of current position } & 10 \\ \text { Academic } & \text { (10) }\end{array}$

Clinical $\quad 35$

Combined $\quad 56 \quad(55)$

Current title (top 5)

Consultant 33

Assistant professor $\quad 22$

Associate professor 19

Senior lecturer $\quad 10 \quad$ (9)

Professor $\quad 6 \quad$ (9)

Other $11 \quad$ (11)

Held leadership position(s) post-Fellowship

Clinical/academic head of department $\quad 22$

Laboratory/research group leadership positions 22

Management/administrative leadership position 62

Ongoing clinical or research collaborations resulting from Fellowship

Yes $\quad 47 \quad$ (47)

No $54 \quad$ (53)

Number of peer-reviewed publications since leaving Fellowship

$0 \quad 16 \quad$ (16)

$1-5 \quad 40 \quad(39)$

6-10 14

$11-15 \quad 5 \quad 5$

$>15 \quad 26 \quad(26)$

Number of survey respondents per question: 101

\section{Perceptions of Fellowship and Its Impact on Survey Respondents}

Respondents identified acquiring clinical expertise, academic/ research opportunities, supervision/mentorship, collegial and multidisciplinary environment, and networking opportunities (social/professional) as being the top five strengths of the UTDRO Fellowship Program (Table 7). Program weaknesses most commonly identified included heavy clinical load (e.g. on-call requirements), insufficient supervision/mentorship (e.g. research guidance, post-fellowship and career development advice, assistance with accommodations, family/ personal issues), limited resources and time for research (Table 7).

Most respondents did not experience any financial stress $(65 \%)$ or social challenges $(74 \%)$ while participating in the program (Table 5). Among those who did report financial difficulty (35\%), around $74 \%$ percent $(26 / 35)$, had relocated to Toronto with their family. Higher costs of living in Toronto, lower fellowship stipends than in their home country, as well as other financial commitments (e.g., relocation costs, family/ child care support, mortgages in home country) were common sources of financial stress among respondents (Table 7). The main social challenges experienced by individuals included having no social network support in Toronto, adjusting to a new city with a family, finding employment for spouse/partner, and communication barriers (Table 7).

Overall, the majority of respondents (92\%) felt that the UTDRO Fellowship exceeded their expectations, wherein $99 \%$ of alumni would recommend the program to others. The vast majority $(96 \%)$ indicated that completing the UTDRO Fellowship had a positive or strongly positive impact on their career development. In comparison with their local RO peers without UTDRO Fellowship training, 74\% of alumni believed they were slightly or much more successful in their careers.

\section{Employment and Scholarly Activities of FRCPC Radiation Oncologists-UTDRO Fellowship Alumni Versus Others}

Current employment and location status, as well as indicators for academic productivity, were identified for $285 / 287$ of FRCPC designees in the comparator cohort (Table 6). Ninety-one percent of UTDRO Fellowship alumni and $89 \%$ of non-UTDRO peers were employed in Canada. All held staff positions in the field of Radiation Oncology. Many individuals from both groups held academic positions, in addition to clinical and/or research positions. University faculty appointments and research position(s) were held by $81 \%$ and 
Table 5 Perceptions of fellowship program and its impact

No. Percent

Overall experience as UTDRO Fellow

$\begin{array}{lrl}\text { Far below expectations } & 0 & (0) \\ \text { Barely met expectations } & 2 & (2) \\ \text { Met expectations } & 6 & (6) \\ \text { Above expectations } & 46 & (45) \\ \text { Far above expectations } & 47 & (47)\end{array}$

Impact of Fellowship on career development

$\begin{array}{lrl}\text { Strongly negative } & 0 & (0) \\ \text { Negative } & 0 & (0) \\ \text { None } & 4 & (4) \\ \text { Positive } & 37 & (37 \\ \text { Strongly positive } & 60 & (59)\end{array}$

Comparison with local radiation oncology peers

Less successful 0

Slightly less successful $\quad 0$

No difference 26

Slightly more successful $\quad 51$

More successful 24

Experienced financial difficulty during Fellowship

Yes 22

Maybe 13

No 66

Experienced social challenges coming to Toronto

Yes 26

No

75

Would recommend the Fellowship Program to others

Yes $\quad 97$

Maybe 3

No 1

Ongoing communication with other UTDRO Fellows
Yes
92
No
9

\section{(0)}

(0)

Number of survey respondents per question: 101

$32 \%$ of UTDRO Fellowship alumni, respectively, compared with $68 \%$ and $10 \%$ for non-alumni peers. Leadership appointments were held by $26 \%$ of UTDRO Fellowship alumni vs. $17 \%$ of the non-UTDRO group; these positions included leads, heads, or directors of clinical, research, or educational programs, as well as leadership roles in regional, national, or international committees and organizations. University of Toronto, Department of Radiation Oncology Fellowship alumni had a higher median number of total publications (14.0 vs. 7.0; $P=.04$ ) and as first author ( 3.0 vs. $1.5 ; P=.002$ ). There was no significant difference in the total number of clinical trials in which an individual was involved since receiving the FRCPC designation between both groups $(P=.14)$.

\section{Discussion}

This study represents the first formal assessment of the UTDRO Fellowship Program, and the collective opinions of its graduates on their training experiences and perceived impact on professional development. Based on the metrics evaluated in this study, the UTDRO Fellowship Program has been successful; the majority of graduates reported positive training experiences and benefits to scholarly output and professional development.

We reported that $68 \%$ of survey respondents considered practicing in Canada upon completion of fellowship training; $35 \%$ (24/69) of these individuals had also completed RO residency training in Canada. Only $31 \%$ of survey respondents were able to find employment in Canada immediately postfellowship; not surprisingly, most of these individuals (71\%; 22/31) had also completed their RO residency training in Canada. The vast majority returned to their home countries or relocated abroad. These findings are consistent with previous reports suggesting that most fellowship graduates practice in a different location from their fellowship training [9], and signifies a perceived shortage of Canadian employment opportunities for newly certified radiation oncologists, which may be a motivating factor for graduate emigration [6]. This perceived shortage of employment opportunities may have also served as motivation to pursue a fellowship in the first place. Respondents cited becoming more competitive in the job market as the fifth most listed reason to complete a fellowship, and without the potential presence of social desirability bias, this may have been reported even more frequently. Indeed, empirical studies have reported that the tight job market in Canada correlates with a spike in fellowship enrollment seen in the late 2000s/early 2010s [10]. Those graduating from residency programs during these surges may have needed a fellowship to act as a bridge until securing a job, or to improve their chances of obtaining a job.

Over the past decade, an upward trend in scholarly output has been observed among Radiation Oncology residents during training [11], possibly due to concerted efforts by RO residency programs to foster research opportunities and mentorship and increase protected research time [12, 13]. Fittingly, research output (e.g., publications, abstracts, grants, collaborations) was reported as one of the highest valued metrics denoting success of fellowship training by graduates surveyed in this study. Respondents reported high levels of academic productivity during their training, with more than $87 \%$ of trainees producing at least one manuscript and abstract as first or co-author (Table 3). A large proportion of respondents $(65 \%)$ remained in academic practice post-fellowship and continued to develop robust research careers. Among radiation oncologists who received their FRCPC designation 
Table 6 Employment and scholarly activities of FRCPC designees (2000-2012)

\begin{tabular}{lllll}
\hline & & UTDRO Fellow $(n=57)$ & Others $(n=228)$ & $P$ \\
\hline \multirow{4}{*}{ Country of employment } & & No. $(\%)$ & No. $(\%)$ & \\
& Abroad & $5(9)$ & $25(11)$ \\
& Canada & $52(91)$ & $203(89)$ \\
& Leadership & $15(26)$ & $39(17)$ & \\
& Research & $18(32)$ & $22(10)$ \\
Publications & Staff oncologist & $57(100)$ & $228(100)$ & \\
& University faculty & $46(81)$ & $155(68)$ & \\
& & Median (range) & Median (range) & \\
& First author & $3.0(0-18)$ & $1.5(0-41)$ & 0.0023 \\
Clinical trials & Senior author & $1.0(0-13)$ & $0(0-81)$ & 0.1324 \\
& Total & $14.0(0-124)$ & $7.0(0-271)$ & 0.0415 \\
& Principal investigator & $0(0-5)$ & $0(0-10)$ & 0.6248 \\
& Total & $1.0(0-5)$ & $1.0(0-11)$ & 0.1380 \\
\hline
\end{tabular}

between 2000 and 2012, those with UTDRO Fellowship training were three times more likely than non-UTDRO peers to hold research appointments, as well as produce more publications. These findings may suggest that research productivity during fellowship training translates to research productivity later in one's career.

Components of the Fellowship Program that could be improved included better training experience related to research, mentorship, fellowship expectations, and alumni engagement (Table 7). The desire for more protected research time, structured supervision of research projects, and clarity of available research projects were common sentiments expressed by the survey respondents. As a program aiming to foster research-oriented physicians, these are important factors to consider as the amount of dedicated research time allocated during training has been shown to be a key determinant of research output [12]. The Fellowship Program has also taken concrete steps to address the findings that $35 \%$ of fellows reported financial stress during their Fellowship. Over the duration of the Fellowship Program, remuneration has increased and our program now adheres to the Professional Association of Residents of Ontario guidelines [14] which ensures that our fellows receive competitive remuneration, commensurate with their experience, and based on university guidance of costs associated with participation in a fellowship program. We have also refined the information provided to our fellows, including practical advice on making the transition as smooth as possible and building a community among our fellows upon arrival. Our Chief Fellows are now tasked with an ambassador role, providing support and advice, as well as setting appropriate general expectations for incoming fellows.

The nature of training provided through the UTDRO Fellowship is primarily the responsibility of the supervisors(s). As there was no explicit curriculum, respondents felt that the formalization of goals and expectations between the fellow and supervisor(s) at the beginning of the fellowship would augment the learning experience and academic productivity.
Respondents also viewed mentorship as crucial to their training and career development, with many reporting supervision/mentorship in the top 5 positive aspects of the fellowship, while it was also reported as one the top 5 worst aspects of fellowship. Many fellows found interactions with their supervisors/mentors to be very positive and helpful for their careers, but a small minority also felt that some supervisors/mentors could have been more available/appreciative. These limited negative experiences existed simultaneously with positive experiences; thus, fellows reported both. Many fellows requested greater faculty guidance in preparing for job readiness, work-life balance, and other issues that may arise during their fellowship. Improving the quality of mentoring may also help to alleviate the social challenges experienced by trainees during the fellowship.

Results of our study have highlighted the inherent value in garnering real-time feedback from presently enrolled fellows, as it facilitates our ability to be nimble and promptly responsive to fellows' dynamic needs. As such, since the completion of this study, a formal mid-fellowship evaluation to assess trainees' progress and satisfaction with the program has been implemented. Various strategies to maintain and engage our extensive alumni network, ranging from establishing a formal UTDRO alumni organization, newsletters, mentorship program, and alumni awards, have also been established or are being explored.

Additional ways our study findings have allowed for tangible improvements within our program include an increased focus on research productivity as an important deliverable both in terms of consolidating learning and facilitating career planning. Enriched educational offerings including research rounds, a journal club dedicated to fellows, and participation in the Strategic Training in Transdisciplinary Radiation Science for the twenty-first century program (STARS21; a competitive program for transdisciplinary training in research skills essential to conducting innovative research in radiation medicine) are now made available and participation is strongly encouraged. 
Table 7 Key themes identified from open-ended survey responses

\begin{tabular}{|c|c|}
\hline Fellowship objectives & $\begin{array}{l}\text { 1. Gain clinical experience in chosen area of interest } \\
\text { 2. Exposure to research opportunities with potential to publish } \\
\text { 3. Travel abroad to obtain another perspective of radiation oncology in a large academic department } \\
\text { 4. Build collaborations with world-class academics } \\
\text { 5. Obtain employment }\end{array}$ \\
\hline Reasons Fellowship fulfilled objectives & $\begin{array}{l}\text { 1. Clinical experience } \\
\text { 2. Research opportunities } \\
\text { 3. Networking } \\
\text { 4. Mentorship } \\
\text { 5. Led to employment }\end{array}$ \\
\hline Best aspects of Fellowship & $\begin{array}{l}\text { 1. Acquiring clinical expertise } \\
\text { 2. Academic/research opportunities } \\
\text { 3. Supervision/mentorship } \\
\text { 4. Collegial and multidisciplinary environment } \\
\text { 5. Networking (social and professional) }\end{array}$ \\
\hline Worst aspects of Fellowship & $\begin{array}{l}\text { 1. Overwhelming clinical load } \\
\text { 2. Lack of supervision/mentorship } \\
\text { 3. Lack of academic/research opportunities } \\
\text { 4. Limited resources and time for research } \\
\text { 5. Lack of a collegial and multidisciplinary environment }\end{array}$ \\
\hline $\begin{array}{l}\text { Factors that hindered productivity during } \\
\text { Fellowship }\end{array}$ & $\begin{array}{l}\text { 1. Insufficient protected research time } \\
\text { 2. Limited collaborative work with other fellows } \\
\text { 3. Inadequate mentorship or supervision } \\
\text { 4. Limited opportunities } \\
\text { 5. Challenges with research (e.g., lack of expertise and resources, time allocation) } \\
\text { 6. Family or personal issues }\end{array}$ \\
\hline Ways Fellowship Program can be improved & $\begin{array}{l}\text { 1. Better programmatic structure and mentorship for research } \\
\text { a. More protected research time } \\
\text { b. More research project supervision } \\
\text { c. Involve fellows in research early during the Fellowship } \\
\text { d. Increase opportunities to collaborate with other fellows and residents } \\
\text { e. Improve access to research opportunities not linked to fellow's clinical supervisor } \\
\text { 2. Improve participation/dedication of mentors/supervisors and consistency of supervision/mentorship } \\
\text { among fellows } \\
\text { 3. Set clear objectives/expectations between fellow and supervisor(s) at start of Fellowship } \\
\text { 4. Provide formal review of progress during Fellowship (e.g., at } 4 \text { months) to allow for adjustments and } \\
\text { targeted actions } \\
\text { 5. Provide support system for personal matters (e.g., child care, work-life balance) } \\
\text { 6. Increase fellow stipends and funds to attend conferences }\end{array}$ \\
\hline Reasons Fellowship was financially difficult & $\begin{array}{l}\text { 1. Higher costs of living in Toronto vs. home country } \\
\text { 2. Fellowship stipend was lower than stipend/salary in home country or other local Fellowship Programs } \\
\text { 3. Relocating with family (e.g., moving costs, supporting family, child care) } \\
\text { 4. Financial commitments in home country (e.g., mortgage) } \\
\text { 5. Visiting family who remained in home country }\end{array}$ \\
\hline $\begin{array}{l}\text { Social challenges experienced coming to } \\
\text { Toronto }\end{array}$ & $\begin{array}{l}\text { 1. No social support network in Toronto } \\
\text { 2. Adjusting to new city with family } \\
\text { 3. Finding employment for spouse/partner } \\
\text { 4. Communication barriers; English was second language for fellow/family } \\
\text { 5. Winter season/cold weather }\end{array}$ \\
\hline
\end{tabular}

The present study has several limitations that should be noted. The accuracy of the current employment and academic output data is limited by the content reported online at the time of the search. Furthermore, comparing the career success and academic productivity of UTDRO graduates with a nonUTDRO cohort was challenging, as no appropriate comparator group was readily available. Employing FRCPC designees who had not completed the UTDRO Fellowship as the comparator had limitations, since it was unknown as to whether those individuals had completed fellowship programs at other institutions or additional forms of post-residency training. The possibility of selection bias is also acknowledged. While the comparator cohort provides an important frame of reference, it is pertinent to note that those who enrolled in our department's formal Fellowship Program may have been more academically inclined prior to the start of the fellowship, and thus may have displayed higher levels research productivity regardless of the Fellowship Program itself. The potential benefits of 
completing a UTDRO Fellowship versus other forms of postresidency training or no training at all can only be inferred from these findings, warranting further investigation.

Another recognized constraint of our study is the selfreporting nature of the survey as it may be subject to recall and responder bias. Difficulty in eliciting physician participation in survey research has long been recognized, primarily due to demands on physicians' time and resources. This is reflected in our study's response rate of $38 \%$, which remains within the range of those reported in similar surveys, varying between 12 and $57 \%$ [4, 15-17].

Additional survey questions that describe the broader impact of the Fellowship Program on employment, such as time to secure employment, number of job applications/interviews before accepting a job offer, and extent of knowledge transfer to a fellow's home country, especially for fellows from LMICs where there is an explicit goal to enhance radiation oncology capacity building and knowledge transfer, merit further consideration. Subsequent evaluations could also be conducted on a regular basis, with supervising faculty being surveyed for a 360-degree assessment of the program.

In conclusion, our study demonstrates the perceived benefits of completing post-residency fellowship training, which may be becoming an expected extension beyond residency for graduates in some North American areas [2]. It highlights potential factors that appear to be most important to those pursuing fellowships, which can help inform academic program directors on strategies to improve recruitment and the overall training experience. We recognize that our findings may not be representative of all Canadian Radiation Oncology fellowship graduates, but we hope that these data will provide a framework for similar programs looking to evaluate and improve their curricula.

Acknowledgements We gratefully acknowledge the efforts of our survey respondents, as well as the staff and faculty of the University of Toronto - Department of Radiation Oncology who have contributed to the success of the Radiation Oncology Fellowship Program. We also thank Marcia Bowen and Catherine Wong for their long-standing involvement as Fellowship Program Coordinators, as well as the Radiation Medicine Program at the Princess Margaret Cancer Centre and the Department of Radiation Oncology at the Odette Cancer Centre for supporting the operations of the program.

Funding Information The authors have no external funding source to declare.

\section{Compliance with Ethical Standards}

Conflict of Interest The authors declare that they have no conflict of interest.

Open Access This article is licensed under a Creative Commons Attribution 4.0 International License, which permits use, sharing, adaptation, distribution and reproduction in any medium or format, as long as you give appropriate credit to the original author(s) and the source, provide a link to the Creative Commons licence, and indicate if changes were made. The images or other third party material in this article are included in the article's Creative Commons licence, unless indicated otherwise in a credit line to the material. If material is not included in the article's Creative Commons licence and your intended use is not permitted by statutory regulation or exceeds the permitted use, you will need to obtain permission directly from the copyright holder. To view a copy of this licence, visit http://creativecommons.org/licenses/by/4.0/.

\section{References}

1. Atun R, Jaffray DA, Barton MB, Bray F, Baumann M, Vikram B, Hanna TP, Knaul FM, Lievens Y, Lui TYM, Milosevic M, O'Sullivan B, Rodin DL, Rosenblatt E, van Dyk J, Yap ML, Zubizarreta E, Gospodarowicz M (2015) Expanding global access to radiotherapy. Lancet Oncol 16(10):1153-1186. https://doi.org/ 10.1016/S1470-2045(15)00222-3

2. Mohamad O, Meyer JJ (2017) Recent trends in radiation oncology fellowship training in the United States. Int J Radiat Oncol Biol Phys 99(3):539-540. https://doi.org/10.1016/j.ijrobp.2017.07.003

3. Ryan J, Khandelwal A, Fasih N (2013) Trends in radiology fellowship training: a Canadian review 2009-2011. Can Assoc Radiol J 64(3):176-179. https://doi.org/10.1016/j.carj.2011.12.015

4. Debenham B, Banerjee R, Fairchild A, Dundas G, Trotter T, Yee D (2012) 2009 Canadian radiation oncology resident survey. Int J Radiat Oncol Biol Phys 82(4):1326-1331. https://doi.org/10. 1016/j.ijrobp.2011.04.030

5. Falit BP, Pan HY, Smith BD, Alexander BM, Zietman AL (2016) The radiation oncology job market: the economics and policy of workforce regulation. Int J Radiat Oncol Biol Phys 96(3):501-510. https://doi.org/10.1016/j.ijrobp.2016.05.029

6. Loewen SK, Halperin R, Lefresne S, Trotter T, Stuckless T, Brundage M (2015) Delayed workforce entry and high emigration rates for recent Canadian radiation oncology graduates. Int J Radiat Oncol Biol Phys 93(2):251-256. https://doi.org/10.1016/j.jirobp. 2015.06.002

7. Nowell LS, Norris JM, White DE, Moules NJ (2017) Thematic analysis:striving to meet the trustworthiness criteria. Int J Qual Methods 16(1):1609406917733847. https://doi.org/10.1177/ 1609406917733847

8. Thorne S (2000) Data analysis in qualitative research. EvidenceBased Nurs 3(3):68-70

9. Mohamad O, Doke K, Marcrom S, Chen AM, Royce TJ, Meyer JJ (2018) A Fellow's fate: employment outcomes of radiation oncology fellowship graduates. Int J Radiat Oncol Biol Phys 102(1):1617. https://doi.org/10.1016/j.ijrobp.2018.04.028

10. Loewen SK, Doll CM, Halperin R, M. Parliament, Pearcey RG, Milosevic MF, Bezjak A, Vigneault E, Brundage M (2019) National trends and dynamic responses in the Canadian Radiation Oncology Workforce from 1990 to 2018. Int J Radiat Oncol Biol Phys 105(1):31-41. https://doi.org/10.1016/j.ijrobp.2019.04.019

11. Verma V, Burt L, Gimotty PA, Ojerholm E (2016) Contemporary trends in radiation oncology resident research. Int J Radiat Oncol Biol Phys 96(4):915-918. https://doi.org/10.1016/j.jirobp.2016.08. 005

12. Gutovich JM, Den RB, Werner-Wasik M, Dicker AP, Lawrence YR (2013) Predictors of radiation oncology resident research productivity. J Am Coll Radiol 10(3):185-189. https://doi.org/10. 1016/j.jacr.2012.06.036

13. Vapiwala N, Moghanaki D, Movsas B (2015) Cultivating tomorrow's clinician scientists: we reap what we sow. Int J Radiat Oncol 
Biol Phys 92(2):206-210. https://doi.org/10.1016/j.ijrobp.2014.12. 038

14. Professional Association of Residents of Ontario. 2020. http:// www.myparo.ca/your-contract/. Accessed 04-14-20 2020

15. Jagsi R, Chronowski GM, Buck DA, Kang S, Palermo J, Committee Association of Residents in Radiation Oncology Executive (2004) Special report: results of the 2000-2002 Association of Residents in Radiation Oncology (ARRO) surveys. Int J Radiat Oncol Biol Phys 59(1):313-318. https://doi.org/10. 1016/j.ijrobp.2003.12.025

16. Wilson LD, Flynn DF, Haffty BG (2005) Radiation oncology career decision variables for graduating trainees seeking positions in
2003-2004. Int J Radiat Oncol Biol Phys 62(2):519-525. https:// doi.org/10.1016/j.ijrobp.2004.10.004

17. Yee D, Fairchild A, Keyes M, Butler J, Dundas G (2005) 2003 survey of Canadian radiation oncology residents. Int J Radiat Oncol Biol Phys 62(2):526-534. https://doi.org/10.1016/j.ijrobp. 2004.10.028

Publisher's Note Springer Nature remains neutral with regard to jurisdictional claims in published maps and institutional affiliations. 